\title{
Os brilhantes do brasileiro: a narrativa passional camiliana em circulação na América portuguesa
}

\author{
Os brilhantes do brasileiro: the circulation of a passional novel by Camilo \\ Castelo Branco in Portuguese America \\ Juliana Maia QUEIROZ* \\ Universidade Federal do Pará (UFPA) \\ Lueny Amanda Oliveira FRANÇA ${ }^{* *}$ (In memoriam)
}

RESUMO: Nosso artigo tem por objetivo investigar a circulação do romance camiliano $O s$ brilhantes do brasileiro (1869) por meio de anúncios divulgados no Jornal do Commercio do Rio de Janeiro, bem como analisar essa narrativa que foi publicada - ao pé da página- na província do Pará, no jornal Diário de Belém na seção Folhetim. Tendo em vista a quantidade de livrarias que anunciavam essa narrativa, e também sua veiculação em destaque na seção Folhetim no Pará, podemos levantar hipóteses sobre o interesse dos leitores por essa obra camiliana. Portanto, saber e entender as obras de maior difusão social naquele século é importante para compreender o gosto dos leitores comuns, assim como identificar os livros com os quais os escritores da época disputavam no competitivo mercado editorial brasileiro da segunda metade do século XIX.

PALAVRAS-CHAVE: Os brilhantes do brasileiro. Novela camiliana. Narrativa passional. Circulação em periódicos.

ABSTRACT: Our article aims to investigate the circulation of the novel Os brilhantes do brasileiro, published by Camilo Castelo Branco in Portugal in 1869, by means of ads published at Jornal do Commercio of Rio de Janeiro, as well as to analyze this narrative that was also published - at the foot of the page - in the province of Pará, in Diário de Belém in the section called Folhetim. Considering the number of bookstores that announced this narrative, as well as its prominence in the Folhetim section in Pará, we can make hypothesis about the readers' interest in this work. Therefore, knowing and understanding the works of greater social

\footnotetext{
* Doutora pela UNICAMP, com pós-doutorado pela UNIFESP e estágio de pesquisa na Universidade ${ }_{\star \star}$ Nova de Lisboa. Professora adjunta de literatura portuguesa na UFPA. E-mail: jumaiaque@gmail.com ${ }^{* *}$ Mestranda em Estudos Literários na UFPA.
} 
diffusion in that century it becomes important to understand the preference of ordinary readers, as well as to identify the books with which the writers of the time disputed in the competitive Brazilian publishing market of the second half of the nineteenth century.

KEYWORDS: Os brilhantes do brasileiro. Camilo Castelo Branco novel. Passional novel. Journal circulation.

\section{Introdução}

No decorrer do século XIX, no Brasil, assim como na Europa, os textos literários eram frequentemente publicados em periódicos. Naquele tempo, esse suporte era o veículo de comunicação de maior alcance e devido ao seu baixo custo, possibilitou a interação significativa entre o público leitor e o texto impresso. Nesse sentido, os jornais foram importantes não só pelo seu conteúdo noticioso e político, mas também pela veiculação das novidades literárias presentes tanto nas seções dedicadas à literatura, como por exemplo a seção Folhetim, quanto na seção de Anúncios, que além da venda de escravos, remédios e roupas, também era destinado à oferta de livros, sobremaneira romances.

À vista do sucesso que essa forma literária provocava entre os leitores, os editores de jornais publicavam, na seção Folhetim, as prosas de ficção de autores consagrados da época e que tinham a preferência do público. Dessa maneira, os editores brasileiros aderiram à estrutura herdada dos franceses, publicando-se diariamente as narrativas ficcionais nos rodapés dos jornais de maneira fragmentada. Sendo assim, as narrativas eram pausadas no clímax dos capítulos, geralmente com a frase: "continua amanhã...”.

Após o desfecho das tramas publicadas nos periódicos, era comum vê-las sendo ofertadas na seção denominada Anúncios nos jornais brasileiros de fluxo contínuo. Assim, os leitores poderiam adquirir as edições impressas dos romances que gostavam e que anteriormente haviam sido veiculados na seção Folhetim.

Nesse sentido, as gazetas oitocentistas foram cruciais para a difusão da literatura no Brasil e, desse modo, contribuíram para o processo de introdução, popularização e consagração do gênero romance. A análise desse suporte, portanto, permite-nos recriar o 
percurso empreendido por determinadas obras que circularam no mercado editorial naquele século, trazendo hoje a possibilidade de aprofundarmos os estudos acerca das práticas de leitura e da história da leitura na América portuguesa.

Com o propósito de nos debruçarmos a respeito da circulação de romances no Brasil, catalogamos as seções Folhetim e Anúncios em dois periódicos oitocentistas: o Diário de Belém, veiculado na província do Pará, e o Jornal do Commercio do Rio de Janeiro, ambos entre 1868 a 1879. A partir dos dados coletados constatamos que a preferência do público leitor apontava para as obras de nacionalidade estrangeira, principalmente francesa e portuguesa. Entre os autores de origem portuguesa, Camilo Castelo Branco foi o romancista mais afamado tanto na capital do Império quanto na província no Norte.

Dentre as obras de Camilo, o romance Os brilhantes do brasileiro alçou significativa notoriedade nos dois periódicos. Publicada em 1869 em Portugal, essa narrativa não tardou a chegar em terras brasileiras, posto que foi anunciada no início de janeiro de 1870 no Jornal do Commercio do Rio de Janeiro. Além disso, essa prosa de ficção foi ofertada tanto pelos livreiros mais modestos quanto pelas livrarias de maior prestígio do Brasil. Na província do Pará, o periódico Diário de Belém publicou este romance na seção Folhetim no ano de 1871. Tendo em vista o leque de livrarias que continham em suas prateleiras essa narrativa no Rio de Janeiro, e também sua veiculação em destaque na seção Folhetim no Pará, tal fator pode nos indicar o interesse dos leitores por essa obra camiliana.

Outrossim, segundo Márcia Abreu (2014), a preferência dos leitores pode permanecer constante durante décadas, e até mesmo séculos, o que explicaria também o fato dessa obra ter sido anunciada no decorrer da década de setenta do Oitocentos, no Rio de Janeiro. Nessa perspectiva, nos propusemos a investigar, a partir dos resultados de nossas pesquisas, com base nos jornais aqui mencionados, a circulação e análise do romance Os brilhantes do brasileiro na América portuguesa.

Na primeira parte do presente artigo, buscaremos mostrar por meio dos anúncios de livros publicados no Jornal do Commercio da capital do Império, a oferta dessa obra literária em diversas livrarias existentes no competitivo mercado editorial carioca. Além disso, saber e entender as obras de maior difusão social naquele século é importante 
para compreender o gosto dos leitores comuns, assim como identificar os livros com os quais os escritores da época disputavam espaço no mercado editorial brasileiro:

\begin{abstract}
Finalmente, parece importante identificar e compreender o gosto dos públicos amplos, fazendo com que a leitura passe a ser um dos elementos relevantes para a história da literatura. A identificação dos títulos de maior sucesso é tarefa relativamente fácil quando se cruzam as diversas fontes disponíveis, como anúncios de venda de livros e catálogos de livreiros, registros de consulta a obras em bibliotecas e gabinetes, apontamentos sobre posse de livros em inventários, testamentos e leilões. Mais difícil é entender o gosto dos leitores. Porém, a análise dos livros preferidos em certo momento poderá revelar a existência de elementos temáticos ou formais recorrentes, que permitam vislumbrar as causas da eleição de determinados conjuntos de obras. [...] Importa perceber a multiplicidade de interesses e gostos numa época, não apenas porque os letrados e os leitores comuns tendem a divergir, mas também porque há cisões no interior do próprio corpo de letrados e de leitores comuns. (ABREU, 2014, p. 43).
\end{abstract}

$\mathrm{Na}$ segunda parte, apresentaremos uma análise da narrativa Os brilhantes do brasileiro que foi propagada entre o público nortista, através do jornal Diário de Belém na província Pará. Embora seja uma narrativa passional, Camilo Castelo Branco, por meio do narrador, satiriza, critica, ironiza e expõe a corrupção moral da burguesia portuguesa em ascensão.

\title{
1. Os brilhantes do brasileiro em meio ao competitivo mercado editorial carioca
}

A sociedade brasileira na segunda metade do século XIX, de maneira geral, era segregada em dois estratos: a primeira era estruturada por brancos nobres e fazendeiros ricos; e a outra, a maior camada, era constituída por negros escravos, mulatos e homens livres. Nessa conjuntura, o Rio de Janeiro era o principal centro econômico, financeiro e cultural do Brasil. Como se sabe, nesse período a cidade já sentia os resultados da chegada da família real portuguesa para o Brasil em 1808, o que proporcionou a abertura dos portos, implementação da imprensa, bem como o surgimento de várias instituições de ensino, por exemplo: a academia militar, escola real de ciências artes e ofício e a biblioteca nacional.

Nesse contexto, a sociedade começa a dar sinais da formação de uma cultura letrada, uma vez que as instituições de ensino, gabinetes de leitura e bibliotecas tinham sido criadas há algumas décadas e o número de letrados aumentava. À vista disso, os 
livreiros estabelecidos na capital do Império anunciavam as novidades literárias nos jornais mais prestigiados e de maior circulação. Dentre eles, estava o Jornal do Commercio, um periódico conservador e considerado uma das fontes oficiais do governo.

Entre os anos de 1868 a 1879, período pesquisado no Jornal do Commercio, localizamos cinquenta e oito títulos de romances do escritor Camilo Castelo Branco, isto é, a presença desse autor foi assídua e significativa durante todo esse recorte temporal. Isso demonstra que ao longo de mais de uma década esse romancista não perdeu prestígio, e que sua popularidade se perpetuava. Consequentemente, essas informações nos dão evidências de que o público leitor carioca apreciava o autor lusitano.

Nesse contexto, vários dos romances de maior sucesso de Camilo Castelo Branco foram anunciados no jornal carioca como, por exemplo, a obra que o consagrou no cânone literário português: Amor de perdição; assim como outras obras muito conhecidas: Amor de Salvação; Novelas do Minho; Coração, cabeça e estômago; A brasileira de Prazins. Romances menos conhecidos do público atual também estampavam a seção de Anúncios: Os brilhantes do brasileiro; O regicida; A caveira do mártir; A enjeitada e Duas épocas na vida.

A obra Os brilhantes do brasileiro foi publicada em Portugal em 1869. E já em dezenove de janeiro de 1870, na edição 19, essa narrativa foi anunciada pela Livraria Cruz Coutinho no Jornal do Commercio, isto é, pouco tempo depois de sua publicação em Portugal, demonstrando que o mercado editorial brasileiro era atualizado e relativamente rápido em importar as novidades literárias. Essa informação comprova também que, diferente do que supõe o senso comum, o Brasil não sofria de um atraso cultural, uma vez que estávamos integrados à circulação de obras do mundo letrado europeu. Vejamos no quadro a seguir todas as livrarias que ofertaram esse romance na seção de Anúncios do Jornal do Commercio naquela década do século XIX:

\begin{tabular}{|l|}
\hline Livraria Cruz Coutinho - Rua São José, n. 75 \\
\hline Livraria de J. Serpa Pinto - Rua S. José, n. 119 \\
\hline Livraria Cruz e Souza- Rua S. José, n.75 \\
\hline Livraria Dupont e Mendonça - Rua Gonçalves Dias, n. 75 \\
\hline Livraria Universal \& amp; H Laemmert - Rua do ouvidor n ${ }^{\text {o }} 68$ \\
\hline
\end{tabular}




\begin{tabular}{|l|}
\hline Livraria Garnier - Rua do Ouvidor, n. 69 \\
\hline Livraria S.G. Azevedo - Rua da Uruguaiana n. 32 \\
\hline Livraria Luso-brasileira - Rua da Quitanda, n. 30 \\
\hline
\end{tabular}

Fonte: Jornal do Commercio

Esses dados revelam o diversificado e competitivo mercado livreiro do Rio de Janeiro na segunda metade do século XIX. Sendo assim, oito livrarias distintas da capital carioca tinham disponível em seus acervos o romance em foco. Três delas situadas na rua S. José, endereço no qual se localizavam as livrarias de preços módicos, ou seja, as edições mais baratas do mercado.

Nas ruas São José, Quitanda, Gonçalves Dias e Uruguaiana o valor do aluguel de uma loja era mais acessível, por isso esses livreiros ofereciam publicações mais baratas. Enquanto que na rua do Ouvidor a locação de lojas era bem mais cara, e lá estavam estabelecidas as livrarias de maior prestígio: A Livraria Garnier e a Livraria Universal dos irmãos Laemmert. Essas duas livrarias foram responsáveis por grande parte da edição, produção e circulação de livros no Rio de Janeiro. Vejamos na imagem a seguir um dos primeiros anúncios de Os brilhantes do brasileiro:

Figura 1

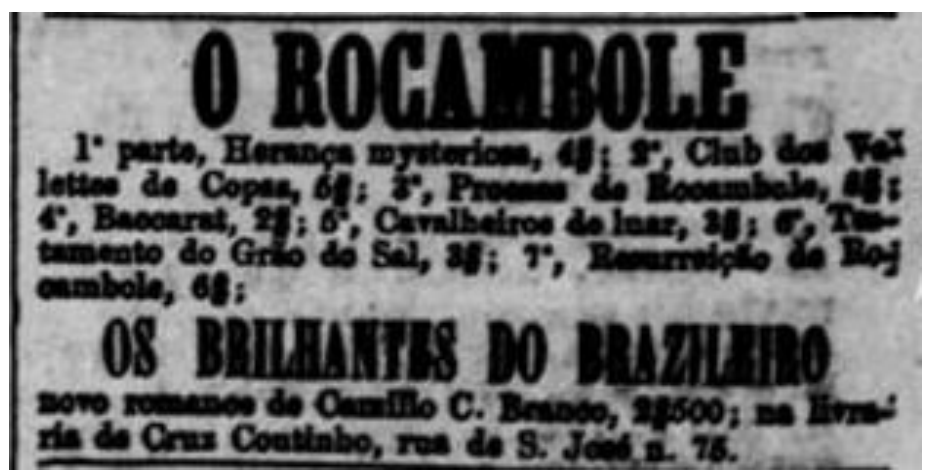

(Jornal do Commercio, edição de 22.01.1870) ${ }^{\dagger 1}$

Nessa imagem, podemos verificar que a obra de Camilo está ao lado de um dos maiores fenômenos do século XIX: O Rocambole, do francês Ponson du Terrail, romancista mais anunciado e que teve seus romances publicados tanto na seção de

\footnotetext{
1 Transcrevemos a seguir o anúncio com atualização da ortografia em português: O ROCAMBOLE $1^{\text {a }}$ parte, Herança misteriosa, 4 \$; 2 Clube de Valetes de copas, 5\$; $2^{\mathrm{a}}$ Proezas de rocambole, 6\$; Baccarat, $2 \$$; Cavaleiros do Luar 3\$; Testamento do Grão de Sal, 3\$; Ressurreição de rocambole, 6\$; OS BRILHANTES DO BRASILEIRO novo romance de Camilo Castelo Branco 2,500\$; na Livraria Cruz Coutinho, rua de S. José n.75.
} 
Anúncios quanto na seção Folhetim do Jornal do Commercio. Terrail publicava a maioria de seus romances em formato de folhetim e suas obras eram difundidas em vários países.

$\mathrm{O}$ fato de que tais autores tenham sido os mais anunciados e o destaque dado a seus romances, tanto em anúncios quanto em folhetins, pode nos indicar que esses escritores eram os preferidos entre o público leitor em suas respectivas nacionalidades: francesa e portuguesa. Quanto ao preço das obras, podemos identificar que os romances de Terrail eram mais caros que os do autor português, embora o romance de Camilo tivesse sido recém publicado.

Isso pode ser justificado pela forte influência da cultura francesa no século XIX em todo o Ocidente. A francofilia foi uma prática comum no Império brasileiro, e isso interferia na vestimenta, arquitetura e no gosto literário da sociedade naquele período. Vejamos a seguir outra oferta do romance do autor lusitano:

Figura 2

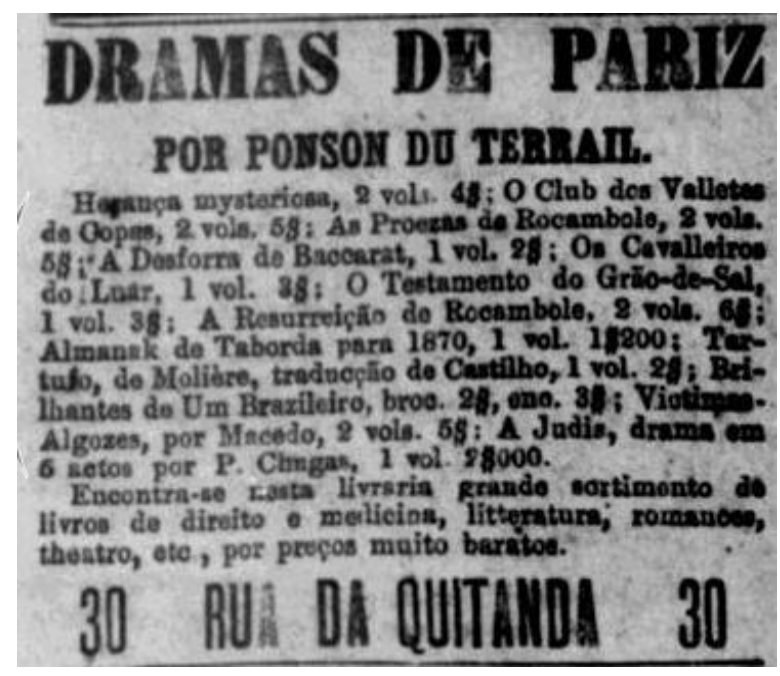

(Jornal do Commercio, edição de 03.03.1870) ${ }^{2}$

\footnotetext{
2 Transcrevemos a seguir o anúncio, com atualização da ortografia em português: DRAMAS DE PARIS, por Ponson Du Terrail; Herança Misteriosa, vols. 4\$; Clube dos valetes de copas, 2 vols. 5\$; Proezas do Rocambole, 2 vols. 5\$; Desforra do bacará 1 vol. $2 \$$; Os cavaleiros do luar 1 vol. $3 \$$; O testamento do 
Esses dados evidenciam para o pesquisador atual a significativa diversidade de títulos disponíveis para compra e venda e também a intensa circulação de livros nacionais e estrangeiros no Oitocentos. Nesse anúncio, Camilo aparece novamente ao lado de Terrail, assim como do brasileiro Joaquim Manuel de Macedo e de seu conterrâneo Pinheiro Chagas, com uma obra de outra forma literária: o drama. Além disso, o livreiro deixa claro que em seu estabelecimento há uma grande quantidade de livros de direito, medicina, dentre outros, ou seja, Camilo não concorria no mercado livreiro somente com romances, mas também com outros gêneros literários e livros de variados temas.

A proximidade entre obras diferentes para públicos amplos demonstra, além da diversidade e quantidade de livros à venda nos anos iniciais da década de setenta do Oitocentos, a presença de Camilo Castelo Branco no processo de popularização do mercado editorial carioca que, com o passar dos anos, se tornava cada vez mais competitivo. Podemos constatar também que no presente anúncio a Livraria Lusobrasileira tinha em seu acervo o romance Os brilhantes do brasileiro com materialidades diferentes: brochura e encadernado, isto é, a narrativa em foco transitou em todos os espaços: nas lojas editoriais mais caras (como as de Garnier e de Laemmert) e nas livrarias menores e mais baratas que continham esse romance em formato brochura; assim, as pessoas com menor poder aquisitivo poderiam adquirir essa obra. Vejamos abaixo mais um exemplo do diversificado mercado editorial carioca:

Figura 3

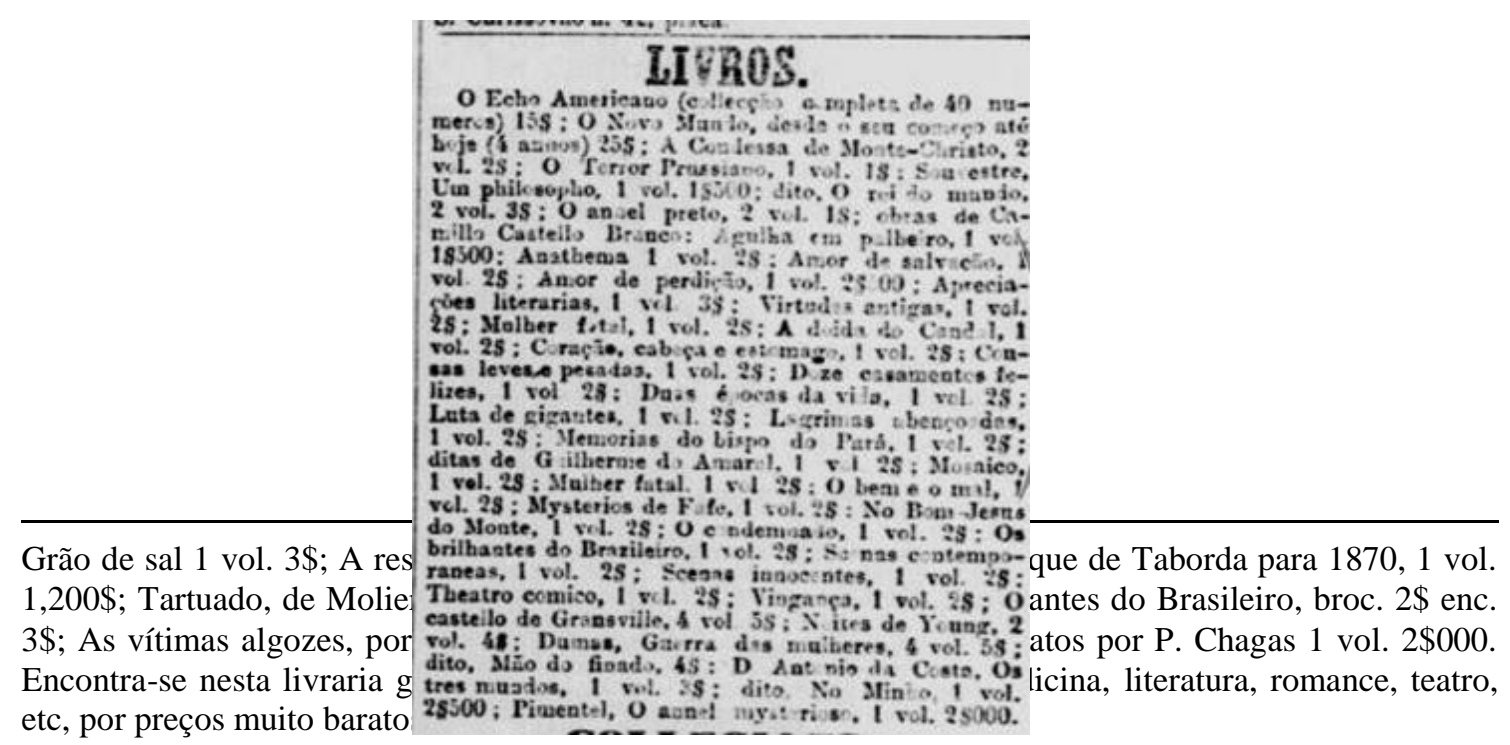


(Jornal do Commercio, edição de 04.01.1875) ${ }^{3}$

O presente anúncio foi publicado pela Livraria de S. G. de Azevedo cinco anos após a narrativa de Camilo ter sido anunciada pela primeira vez. Por meio de nossa pesquisa, constatamos que essa narrativa foi anunciada nos anos de 1870, 1872 e 1875 no Jornal do Commercio. Isso significa que esse romance ainda permanecia em circulação na capital do Império tempos depois de sua publicação e, possivelmente, no gosto do público.

Além disso, o anúncio da livraria $S$. G. de Azevedo que contém vinte e quatro obras camilianas ofertadas simultaneamente, pode nos indicar que anunciar os romances de Camilo Castelo Branco era uma aposta forte o suficiente para ampliar o número de assinantes e de vendas. Quanto aos preços, constatamos que pouco variava: entre 2 mil e 3 mil réis, sendo que os romances desse autor português eram relativamente baratos, se comparados às obras de Paul de Koch e Ponson du Terrail.

Os significativos registros de anúncios do romance Os brilhantes do brasileiro permitem não apenas recriar os rastros da circulação dessa obra literária no Brasil, bem como resgatar esse título quase desconhecido do público leitor atual, afinal, como mostram os dados evidenciados anteriormente, esse romance circulou em diversas lojas de livros no Rio de Janeiro na segunda metade do século XIX. Nesse sentido, tendo em vista que esse romance foi anunciado em 1870, 1872 e 1875, ou seja, em um espaço

\footnotetext{
3 Transcrevemos a seguir o anúncio, com atualização da ortografia em português: O echo americano (coleção completa de 40 números) 15\$; O novo mundo desde o seu começo até hoje (4 anos) 25\$; A condessa de monte cristo 2 vol. $2 \$$; O terror prussiano 1 vol. $1 \$$; Souvetre, um filósofo 1 vol. $1 \$$; dito, O rei do mundo 2 vol. 3\$; O anel preto, 2 vols. 1\$. Obras de Camilo Castelo Branco: Agulha em palheiro 1 vol. 1 \$500; Anátema 1 vol. 2\$; Amor De Salvação 1 vol, 2\$; Amor de perdição 1 vol. $2 \$$; Apreciações literárias 1 vol. $3 \$$ Virtudes Antigas, A mulher fatal 1 vol, $2 \$$; A Doida Do Condal 1 vol, 2\$; Coração, cabeça e estômago 1 vol, 2\$; Coisas Leves e Pesadas 1 vol, 2\$; Doze Casamentos Felizes 1 vol, 2\$; Duas Épocas Da Vida 1 vol, 2\$, Luta de gigantes 1 vol, 2\$; Lágrimas abençoadas 1 vol, 2\$; Memórias Do Bispo Do Grão-Pará 1 vol, 2\$; Memórias do Guilherme do Amaral 1 vol, 2\$; O bem e o mal 1 vol, 2\$; Mistério de fafe; $\mathrm{O}$ bom jesus do monte 1 vol, $2 \$$ Os brilhantes do Brasileiro 1 vol, $2 \$$; cenas contemporâneas, 1 vol. $2 \$$; Teatro Cômico 1 vol. $2 \$$; Vingança 1 vol. $2 \$$; O castelo de Grensville, 4 vol. 5\$; Noites de Young, 2 vol. 4\$; Dumas, Guerra das mulheres, 4 vol. 5\$; Dito, A mão do finado 4\$; D. Antonio da Costa, Os três mundos 1 vol, $3 \$$; Dito, No Minho, 1 vol. $2 \$ 500$; Pimentel, O anel misterioso 1 vol. $2 \$ 000$.
} 
relativamente curto de tempo, podemos, então, inferir que essa obra pode ter sido um sucesso de público e de vendas, justificando, assim, a retomada desses anúncios ao longo dos anos aqui mencionados.

Nesse primeiro momento, nosso foco foi apresentar alguns anúncios que continham o romance Os brilhantes do brasileiro com o propósito de viabilizar a discussão acerca do trânsito dessa narrativa no Brasil, especificamente no maior centro econômico e cultural da época: o Rio de Janeiro. Esses dados mostram uma vasta lista com variedade de gêneros literários, livros de diversos assuntos, assim como um leque considerável de livrarias, que anunciavam diariamente obras nacionais e estrangeiras. Passaremos a seguir à circulação do romance Os brilhantes do brasileiro na província do Pará, região na qual Camilo obteve notoriedade também na seção Folhetim.

\section{Ao pé da página: a circulação da novela passional de Camilo Castelo Branco entre o público leitor no Pará}

Na primeira metade do século XIX, o surgimento das publicações de romancesfolhetins em jornais que circulavam na França foi um dos acontecimentos de maior importância no âmbito literário. Essa prática logo se tornou um sucesso e se difundiu pelo Ocidente. Com efeito, isso modificou a maneira de acesso aos livros dos escritores consagrados e dos romances mais aclamados da época tanto na Europa quanto no Brasil. Consequentemente, tal fato aguçou e direcionou o interesse do público leitor as ao gênero romance.

No território brasileiro, no decorrer do Oitocentos, os romances-folhetins ocupavam um espaço específico nos jornais - o pé da página - no qual eram publicados textos de cunho literário ou de entretenimento. Essa prática foi importante para a difusão do gênero romance no Brasil, tendo em vista que os periódicos eram o veículo de comunicação mais barato e consumido pela sociedade. À vista disso, nos propusemos a investigar e analisar a circulação dessa forma literária também na província do Pará na segunda metade daquele século.

De acordo com Fontes (2016), nesse período o território paraense desfrutava do áureo ciclo da borracha. Com efeito, Belém passou a ser um dos espaços de maior fluxo de mercadorias na Amazônia, abrigando diversas camadas sociais que cobravam do poder público a necessidade de melhoramentos urbanos, tais como: casas, portos, ruas, 
praças etc. Nesse sentido, a economia baseada na extração do látex provocou um dos momentos significativos da história paraense: a Belle Époque. Consequentemente, diversas instituições de cunho intelectual e cultural surgiram, a exemplo do Teatro da Paz (1878), do Grêmio Literário Português (1867) e do Museu Emílio Goeldi (1871).

Embora distantes dos principais centros urbanos, os jornais que circulavam em Belém mantinham os leitores informados sobre as notícias do Império. Esses periódicos tinham caráter noticioso, político, religioso, conservador ou liberal e comumente publicavam textos extraídos de jornais de outras províncias como, por exemplo, do Jornal do Commercio do Rio de Janeiro.

Segundo Germana Sales (2007), existiram entre 1822 e 1900 cinquenta e quatro jornais em circulação em Belém, sendo que a partir da segunda metade do Oitocentos, o crescimento de periódicos que reservavam espaço para publicações literárias aumentou vertiginosamente, uma vez que vinte e nove jornais veiculavam no rodapé das páginas romances-folhetins:

Para fundamentar esta exposição, apresento a seguir dados relativos a cinco jornais, em que a ocorrência da publicação folhetinesca era constante - Gazeta Oficial, Jornal do Pará, Diário de Belém, Liberal do Pará e A Folha do Norte. Nesses periódicos circularam, diariamente, textos literários de vários gêneros: "romance-folhetim", "romance", "romance de cavalaria", "novela", "conto", "crônica", "crônica religiosa", "crônica política", "crônica humorística", "crônica de viagem", "poesia", "farsa", "lenda" e "texto reflexivo". Os assuntos também eram diversificados: amor, peripécias, desilusões amorosas, dramas familiares. As colunas de Variedades, Miscellanea, Litteratura ou Folhetim apresentavam uma diversidade das práticas de escrita que romperam com os gêneros cristalizados da poética clássica. (SALES, 2007, p. 46, grifo meu).

O estudo de Sales (2007) assinala o jornal Diário de Belém como um dos principais jornais que divulgavam textos literários no Pará. Nossa pesquisa realizada em torno desse periódico evidenciou a presença marcante do romancista Camilo Castelo Branco, que foi o autor português mais anunciado e que obteve uma de suas obras publicadas na seção Folhetim. A circulação de romances-folhetins camilianos na imprensa paraense foi objeto de estudo de alguns pesquisadores, a exemplo de Neila Lima $^{\ddagger}$ e Cláudia Paiva ${ }^{\S}$. Os estudos dessas pesquisadoras ratificam a notoriedade do

\footnotetext{
‡ LIMA, Neila Mendonça Garcês. As narrativas camilianas no espaço folhetim do Diário do Gram-Pará na década de 1860. Dissertação (mestrado) - Programa de Pós-Graduação em Letras, Universidade Federal do Pará, Belém, 2014.
} 
escritor lusitano diante do público nortista, uma vez que trazem à luz os romances de Camilo que foram publicados nos principais jornais da província do Pará:

\begin{abstract}
Dos jornais já pesquisados até o momento, identificou-se a presença de narrativas do escritor português na A Província do Pará, jornal que circulou entre 1876 e 1908, onde constaram, entre os anos de 1877 e 1900, duas publicações no espaço folhetim, quais sejam, A inocência das aldeias, em 1879 e Duas páginas das minhas memórias d'além da campa na águia de ouro em 1886 [...] No jornal Liberal do Pará, nos anos de 1871 a 1883, constatouse a presença de um romance do autor: A brazileira de Prazins cujos primeiros capítulos foram publicados inicialmente em 1882 na revista "A Arte de Lisboa", em Portugal. O primeiro jornal de circulação diária na cidade, o Diário do Gram Pará - publicado entre os anos de 1853 e 1892 - fez circular entre os leitores da capital, romances de Camilo Castelo Branco, autor de grande presença nos rodapés jornalísticos locais. (LIMA, 2014, p. 45-46, grifo do autor)
\end{abstract}

Neila Lima (2014) afirma ainda que no jornal Diário do Gram-Pará foram publicados durante a década de sessenta do Oitocentos mais três romances camilianos: Coisas espantosas, A neta do arcediago e $O$ arrependimento. Nesse sentido, observa-se que os periódicos paraenses difundiram uma quantidade significativa das obras de Camilo e também textos literários de autoria portuguesa, tendo em vista que o jornal Diário de Belém divulgava em suas seções diversos textos de escritores lusitanos, tais como: crônicas de Teixeira Vasconcelos, Ramalho Ortigão e Alexandre Herculano; poemas de Mendes Leal e Pinheiro Chagas; e prosas de ficção de Camilo Castelo Branco e Bulhão Pato.

$\mathrm{O}$ interesse dos editores dos jornais em publicar textos lusitanos pode ser justificado pelo fato de que alguns editores e donos de jornais eram de nacionalidade portuguesa e, por isso, davam espaço para os autores de sua pátria. Além disso, o número de portugueses que residiam em Belém naquele período era significativo. De acordo com Fontes (2016), a habitação de portugueses no Pará era expressiva, pois os dados referentes ao consulado português de Belém do século XIX, disponíveis no Grêmio Literário Português, revelam que no ano de 1871 existiam pelo menos 3.001 portugueses cadastrados no consulado. No ano seguinte ocorreu um aumento de aproximadamente 499 habitações portuguesas, provocando um salto para 3.500 habitantes lusitanos oficialmente residentes em Belém em 1872. De acordo com essa

\footnotetext{
$\S$ PAIVA, Cláudia Gizelle Teles. Entre jornais, livrarias e gabinetes de leitura: a circulação dos romancesfolhetins camilianos no Pará oitocentistas. Dissertação (mestrado) - Programa de Pós-Graduação em Letras, Universidade Federal do Pará, Belém, 2017.
} 
estudiosa, a população portuguesa nesse período representava $1,27 \%$ da população do estado.

\begin{abstract}
A imigração para a região era antiga e se ampliou com o advento da exploração da borracha. O período de 1870 a 1910 é considerado pela historiografia regional como a fase áurea da exploração do látex. Neste período, a imigração, não só de portugueses, mas, de espanhóis, italianos e árabes, foi muito intensa, principalmente para as capitais do Pará e Amazonas. Belém torna-se uma cidade cosmopolita e o período destas transformações sociais não nos parecem tão curto. É a grande concentração dos imigrantes portugueses, em Belém, capital do estado, o que deu à cidade uma visibilidade da cultura portuguesa, até hoje. (FONTES, 2016, p. 78)
\end{abstract}

Podemos inferir, portanto, que as publicações de escritores portugueses em terras nortistas tenha sido também uma forma de cativar esses imigrantes, haja vista que a quantidade de portugueses, possivelmente letrados, era considerável. Isso pode ter contribuído para a popularização desses literatos também entre o público nativo.

Nesse contexto, as pesquisas de Cláudia Paiva (2017) e Neila Lima (2014), assim como a pesquisa desenvolvida por nós em torno do jornal Diário de Belém, demonstram que a preferência do público paraense se direcionava, em especial, ao romancista Camilo Castelo Branco** . Esse periódico veiculou no rodapé de suas páginas o romance Os brilhantes do brasileiro no ano de 1871, no mês de março, preenchendo cinco colunas, sendo que o referido jornal publicou catorze dos trinta capítulos ${ }^{\dagger \dagger}$ dessa obra tendo o primeiro número figurado na edição 58 daquele ano. Vejamos a distribuição dos capítulos do romance Os brilhantes do brasileiro no Diário de Belém:

EDIÇÃo
58
59
60
61
62
63

DIA DE PUBLICAÇÃO
14.03 .1871
15.03 .1871
16.03 .1871
17.03 .1871
18.03 .1871
19.03 .1871

CAPÍTULO
I
II
III e IV
IV e V
V e VI
VI e VII

\footnotetext{
** FRANÇA, L. A. O.; QUEIROZ, J. M. A presença de Camilo Castelo Branco no periódico Diário de Belém. In: Tânia Sarmento Pantoja. (Org.). E - book do V Congresso de Estudos Linguísticos e Literários na Amazônia. 1ed. Belém: Programa de Pós - Graduação em Letras -UFPA, 2016, v. 2, p. 110-123.

${ }^{\dagger \dagger}$ Devemos levar em consideração que os dados relativos ao ano de 1871 do jornal Diário de Belém não estão completos, por isso tanto na Hemeroteca Digital quanto na Fundação Cultural do Pará há somente os seguintes registros: 01.01.1871 a 31.03.1871, sendo que as edições 71 e 72 estão mutiladas, por essa razão não podemos visualizar se o romance camiliano foi veiculado nessas últimas edições disponíveis. Por isso, não é possível afirmar que a obra foi publicada em sua completude, porém, acreditamos que sim, pois não faria sentido iniciar o romance-folhetim sem finalizá-lo. Ademais, as edições 64, 65, 66, 67 e 70 a narrativa de Camilo ocupou o rodapé da primeira e da segunda página do referido periódico, o que pode indicar o interesse do público leitor.
} 


$\begin{array}{lcc}64 & 21.03 .1871 & \text { VII e VIII } \\ 65 & 22.03 .1871 & \text { IX } \\ 66 & 23.03 .1871 & \text { X } \\ 67 & 24.03 .1871 & \text { XI e XII } \\ 68 & 25.03 .1871 & \text { XIII } \\ 70 & 29.03 .1871 & \text { XIV }\end{array}$

Fonte: Diário de Belém.

É sabido que Camilo foi um dos poucos escritores que conseguiram viver das letras no século XIX. Diferentemente de outros grandes nomes (Garret, Herculano, Antero de Quental e Eça de Queirós) provenientes de famílias de posses ou que ocupavam outros cargos e não viviam apenas de seus escritos, Camilo Castelo Branco não era de origem nobre e construiu sua carreira escrevendo romances, novelas, crônicas, traduções de livros, peças e poesias que eram publicados principalmente nos jornais portugueses da época. Esse suporte possibilitou a introdução, ascensão e consolidação de Camilo Castelo Branco no cânone português e, dessa maneira, contribuiu tanto para sua carreira quanto para o seu sustento e, por isso, o autor estava sempre atento ao gosto dos leitores.

De acordo com Jacinto do Prado Coelho (2001), de maneira geral, Camilo buscava aproximar suas narrativas aos sucessos da época como, por exemplo, o aclamado romance Os mistérios de Paris, do francês Eugène Sue, publicado em folhetim. Tendo em vista a boa recepção que essa prosa de ficção obteve entre os leitores, Camilo traz à luz o romance Os mistérios de Lisboa (1854), narrativa em que tanto o enredo quanto o título se assemelham com o romance do autor francês. Segundo Márcia Abreu (2014), isso era uma das fortes características dos escritores da época, principalmente daqueles que viviam exclusivamente das letras, pois era necessário sempre agradar os leitores e, assim, aumentar as vendas e assinaturas dos jornais para satisfazer também os editores:

O sucesso dos folhetins e, especialmente, de determinadas obras veiculadas nos rodapés dos jornais afetava também os escritores que, em geral, estavam atentos aos interesses do público, seja no intuito de atendê-los ou contrariálos. Os folhetins modificaram a forma de composição dos textos, não apenas do ponto de vista das escolhas formais e temáticas, mas também do ritmo de escrita e das pressões exercidas sobre os escritores que passavam a conhecer a reação do público ao mesmo tempo em que compunham suas obras. O surgimento dos folhetins afeta também outro elemento de contexto que costuma ser pouco considerado nas histórias literárias convencionais: a profissionalização do trabalho do escritor, que passou a contar com mais um elemento no leque de atividades que tinha de desempenhar. Aqueles que 
desejavam viver do ofício de escrever tentavam aproximar suas narrativas das apresentadas em romances de sucesso, ao mesmo tempo em que sentiam a concorrência dessas obras, publicadas, muitas vezes, em traduções sem pagamento de direito autoral. (ABREU, 2014, p. 41)

Conforme Coelho (2001), a produção romanesca de Camilo comumente tem um conflito central: nobreza x dinheiro x paixão. E seus enredos obedecem a uma fórmula, sempre com o propósito de satisfazer as expectativas do público leitor. $\mathrm{O}$ romance passional Os brilhantes do brasileiro atende ao esquema narrativo elencado por (Coelho, 2001, p. 389):

"[...] a mundivalência camiliana deduz-se que na modalidade mais frequente do amor correspondido seriam dois, em alternativa, os modelos narrativos: Desejo $\rightarrow$ Ação iniciada para satisfazer $\rightarrow$ Obstáculo $(\mathrm{s}) \rightarrow$ Luta $\rightarrow$ Vitória (união definitiva); ou, com desfecho infeliz: Desejo $\rightarrow$ Ação iniciada para satisfazer $\rightarrow$ Obstáculo $(\mathrm{s}) \rightarrow$ Luta $\rightarrow$ Derrota (separação definitiva).

Obedecendo ao modelo estabelecido por esse estudioso, o enredo da narrativa em foco se configura da seguinte forma: a trama se passa entre 1838 e 1863, em Lisboa e no Porto. A fidalga Ângela de Noronha, filha do senhor do paço de Gondar, Simão de Noronha, apaixona-se pelo estudante de medicina Francisco Costa, um plebeu, irmão de Joana, costureira, e filho de um sacristão.

Os dois trocam cartas de amor que são entregues e acobertadas pela fiel escrava de Ângela, Vitorina. Nesse sentido, a temática do conflito amoroso pela diferença de estrato social, tema recorrente na obra camiliana, também se faz presente nessa narrativa, na qual o pobre filho do sacristão almeja se casar com uma fidalga, mas não tem interesse em seu título nobre:

[...] é isso, é isso o meu amar, o meu delirar, a minha inofensiva vertigem, que não tem nada que ver com o nascimento, nem com os haveres de Ângela. Não sei quem é, não conheço, não quero conhecer a filha do general Noronha, a rica herdeira, a fidalga que tem no seu paço de Gondar retratos de seus avós que fundaram a monarquia portuguesa. Quem eu conheço e adoro é uma mulher que se chama Ângela, que tem no rosto uma luz celestial, e essa luz ma representa de geração divina. Ali há sinal de origem mais alta. Eu vou buscá-la no céu; não a procuro na fundação da monarquia. (BRANCO, 2006, p. 42)

As correspondências trocadas pelos amantes chegam às mãos da tia que criou Ângela, Beatriz, que estava tentando há um tempo, sem sucesso, arrumar um marido para sua sobrinha que resistia a todos os pretendentes sugeridos. A partir desse acontecimento surgem os obstáculos: Ângela é renegada pelo pai e é obrigada a ir para 
um convento; sua tia má exige o dinheiro anteriormente emprestado para o custeio do estudos de Francisco Costa e, consequentemente, isso gera a interrupção da faculdade do rapaz; a falência de sua família; a venda de sua casa e a morte de seu cunhado, em razão do desgosto de ver sua vida ruir em desgraça.

Dois anos após esses eventos narrativos, D. Beatriz de Noronha morre perante o remorso de ter causado a morte do merceeiro, cunhado de Francisco. Porém deixa uma significativa quantidade de missas pagas para serem rezadas em seu nome, o que revela a tortuosa crença de que o dinheiro seria suficiente para salvar sua alma diante de suas atitudes cruéis. Acerca disso, o narrador onisciente intruso ironiza a atitude da fidalga:

\begin{abstract}
E posto que a crítica e a medicina presumam que D. Beatriz haja sucumbido a uma cistite, ou qualquer outra moléstia mais ou menos grega, é certo que a velha, para lograr o espectro do merceeiro, deixou um testamento de $960 \$ 000$ réis para missas por sua alma de esmola de 240. Quatro mil missas! O diabo que se atreva a levar alma com tal recomendação, se é capaz! (BRANCO, 2006, p. 52)
\end{abstract}

Sendo assim, Ângela tem permissão para deixar o mosteiro. Desamparada, a fidalga se abriga no Minho em um palacete de uma amiga que conhecera no convento, Rita Barrosas, resgatada do mosteiro por seu irmão, Hermenegildo Fialho, que havia voltado do Brasil com grande fortuna. A pressão, súplicas e chantagens do ricaço e também de sua irmã, Rita, obrigam a protagonista a casar com Hermenegildo, vinte e cinco anos mais velho, acreditando que, devido a sua saúde frágil, o ricaço logo morreria.

Contente com seu noivado, Fialho compra brilhantes para sua amada avaliados em milhares de réis. Em janeiro de 1842, os recém-casados se mudam para o Porto, na rua do Bispo, e Ângela descobre o paradeiro de Joana e de seu amado. O remorso e a culpa pela desgraça de ambos nunca a deixaram tranquila; por isso ela decide vender os brilhantes dados pelo seu marido para que Francisco volte a estudar e proporcionar uma vida menos degradante à Joana.

Essa decisão desencadeia um dos principais conflitos da trama, uma vez que Vitorina é apreendida por desconfiarem que os brilhantes que ela vendeu, e posteriormente pagou para que colocassem pedras similares, não pertenciam a ela, mas a seus amos. Com efeito, Hermenegildo é chamado para reconhecer a possível ladra e, assim, a escrava é presa. Ângela depõe e declara a escrava como inocente, e que os 
brilhantes foram dados para vender e doar para a caridade, mas se recusa a declarar os favorecidos.

Por conseguinte, devido à desconfiança do marido, a fidalga se opõe a ir para um convento, deixa as joias de sua mãe para ressarcir o brasileiro, e procura abrigo no recinto de Joana. Hermenegildo volta ao Brasil pela vergonha de possivelmente ter sido traído e morre pouco tempo depois.

Em 1850, três anos após a separação do brasileiro, Ângela e Francisco se reencontram e se casam. A partir desse momento, de acordo com Coelho (2001), a narrativa passa pelo processo de 'luta', pois embora casados, as personagens não conseguem conviver em harmonia com a hipócrita sociedade, devido ao fato de que a opinião pública não concordava com a união da antiga esposa de Fialho com o agora médico Francisco Costa.

Por essa razão, os dois se mudam para o interior de Portugal e reconstroem suas vidas. Passados dois anos, o pai de Ângela, cego e intitulado conde de Gondar, procura a ajuda do médico que estava curando cegos nas redondezas. Costa opera o velho e decrépito conde. Curado, ele reconhece sua filha renegada, pede perdão e passa mais dez anos ao redor dela que lhe deu mais seis netos, e é intitulada ao final da trama como condessa de Gondar.

Embora essa narrativa se encaixe perfeitamente no modelo das novelas passionais camilianas elencado por Coelho (2001), na qual os amantes têm um final feliz, Camilo utiliza-se desse espaço para criticar duramente a sociedade burguesa em ascensão. Por meio do narrador, denuncia a falsa moral dessa camada social e expõe o sistema lucrativo da venda de títulos. Utiliza-se do escárnio, sátira e ironia para desnudar o comportamento e os costumes portugueses do meio popular.

No folhetim Os brilhantes do brasileiro, publicado no Diário de Belém, em quatorze de março de 1871, há uma nota de rodapé muito importante para os leitores da América portuguesa, mas que não consta na edição do romance à qual tivemos acesso: "Brasileiro chamam em Portugal aos portugueses que residiam no Brasil algum tempo, e que voltam com fortuna" (Diário de Belém, edição 58, p. 1). Essa definição é de suma importância para entender a narrativa, pois o brasileiro nesta narrativa trata-se de Hermenegildo Fialho.

O Brasil possui, para Camilo, uma concretude que não tinha para Eça: é um espaço em que, na maioria das vezes, as fortunas são ganhas com trabalho, um 
trabalho que não deixa espaço para refinamentos. [...] O Brasil é em qualquer parte, pois qualquer parte pode servir como espaço de tentativa de enriquecimento. Mas, na ficção camiliana, o Brasil concreto, do outro lado do Atlântico, é por excelência o espaço que ocupa esse papel. É de lá que parte, na grande maioria dos casos, o dinheiro que irá, depois, ser gasto em Portugal. (OLIVEIRA, 2004, p. 11)

No romance em foco, o brasileiro é um dos personagens que Camilo satiriza com frequência ao empregar diversos adjetivos de zombaria no decorrer da narrativa, tais como: "roliço devasso", "corpulência redonda", "imaculado capitalista" ou "vítima deplorável da perversão dos costumes". Ele é um personagem incapaz de tomar decisões sozinho, uma vez que pede que seus amigos julguem e condenem o comportamento e o destino de seu casamento com a fidalga após ela se recusar a declarar com quem gastou o dinheiro obtido com a venda dos brilhantes.

Nesse sentido, o terceiro capítulo denominado "Retratos do natural" é dedicado a expor a hipocrisia e a falsa moral do caráter dos amigos do brasileiro: "Interrompa-se a apóstrofe, e desenhemos as proeminências morais características destes sujeitos invocados a conferir e alvidrar num pleito de honra". (BRANCO, 2006, p. 13).

Assim, o narrador descreve os três amigos de Fialho. Atanásio da Silva era contrabandista, flagrou o adultério de sua esposa, mas a perdoou passados quinze dias. Frequentemente sua mulher costuma julgar o comportamento e a moral alheia, embora não tivesse dignidade para tal. Pantaleão Guimarães era boêmio e traficante de escravos. Apaixonara-se por uma prostituta e casara-se com ela. Joaquim Bernardo: gandaieiro, estúpido, em sua mocidade roubava açúcar no Terreiro do Paço, casou-se com uma mulher assanhada.

Com tais esclarecimentos, o narrador coloca em xeque o prestígio e a veracidade dos jornais oitocentistas que comumente enalteciam os capitalistas e suas senhoras, e também elogiavam as damas que promoviam bailes para a burguesia. Vejamos a seguir os comentários do narrador acerca das esposas de Atanásio da Silva, Pantaleão Guimarães e Joaquim Bernardo, respectivamente:

\footnotetext{
Conforme à justiça e às manhãs do Porto, a firma de Atanásio é das mais acreditadas na praça, e as gazetas, quando escrevem Atanásio José da Silva, antepõem-lhe ao nome os adjetivos honrado e probo; e, se acontece ir para Caldas ou praias com a mulher, vai sempre o "honrado capitalista com sua virtuosa esposa”. (BRANCO, 2006, p. 14, grifo nosso)
} 
E, de efeito, D. Francisca Mendes, neste ano de 1847, já logrou a satisfação de se ver também caluniada de "esposa virtuosa" nas gazetas. (BRANCO, 2006, p. 14, grifo nosso)

Esta dama já se viu num periódico, em que se dava conta dum seu baile, nomeada de "ilustre e distinta". Ambos os epítetos lhe enquadram, ocultos os substantivos. Não a tratavam de virtuosa, porque o localista receou que o termo, revendo ironia, lhe fechasse as portas do segundo baile. (BRANCO, 2006, p. 15, grifo nosso)

Dessa maneira, o narrador, por meio da ironia, expõe a corrupção moral dos amigos de Hermenegildo e de suas esposas. O capítulo seguinte denomina-se "Tribunal de Honra", no qual os confidentes de Fialho são convocados para julgar e decidir o futuro de Ângela, a esposa supostamente adúltera. O narrador atribui diversos comentários irônicos para nominar as falas das personagens: "honrados juízes da dignidade", "fiscal da misericórdia", além de qualificar tal tribunal como "uma cena ridícula", tendo em vista a falta de escrúpulos dos juízes. Assim, esses personagens adaptam a moral às suas conveniências, pois para eles, os valores só têm sentido quando promovem privilégios sociais ou financeiros. É o que explica Tatiana Moysés:

\footnotetext{
Os personagens construídos a partir desta perspectiva corroboram os conceitos morais quando estão expostos à opinião pública, mas os ignoram no âmbito privado. Como resultado da representação, conquistam respeito e prestígio. Assim, Camilo denuncia que na sociedade oitocentista não é necessário seguir os conceitos morais, pois basta corroborá-los publicamente. (MOYSÉS, 2011, p. 85)
}

Nesse cenário, os juízes decidem impor a Ângela o que foi decidido em seu julgamento: sua ida para um convento. No entanto, a fidalga afronta os juízes, indo de encontro ao comportamento da mulher submissa da época, e os ofende, se recusando a ir para um convento, visto que isso claramente marcaria sua condenação de adúltera perante a sociedade, e permanece se recusando a revelar o destino do dinheiro: “ - Ainda que lhes diga o nome dele, os senhores não conhecem os pobres honrados; conhecem somente os infames ricos" (BRANCO, 2006, p. 75).

No capítulo vinte e três, intitulado ironicamente de "Homens Honestos", o narrador esclarece o que ocorreu com os confidentes de Fialho depois de seis meses de sua morte. As personagens revelam o roubo do patrimônio do brasileiro, haja vista que Fialho queria que parte de sua fortuna fosse destinada para sua esposa Ângela, 
depois de ter descoberto sua inocência, mas eles não encaminharam nada à fidalga. "Abriram-se os buchos, e fecharam-se as consciências destes membros do tribunal de honra onde Ângela foi condenada à infâmia e à pobreza”. (BRANCO, 2006, p. 98). Além disso, a amante de Fialho, Rosa Catraia, frequentava os bailes da burguesia com as joias dadas por Ângela para ressarcir o prejuízo dos brilhantes.

No epílogo desse romance, o narrador esclarece o fim dos três "fétidos" amigos de Hermenegildo e, desse modo, expõe o esquema de compra de títulos por meio da burguesia, uma vez que todos esses desonrosos cidadãos obtiveram títulos de barões, assim como a amante de Fialho:

Rosa Catraia é, pois, baronesa de Vilar d'Amores, título um tanto lírico e romanesco, bem ajustado às escarlates bochechas e túrgidos seios que ressumbram bestidade, saúde, alegria e lubricidade seródia. As outras baronesas, bastante mais avelhantadas, representam os estragos da corrupção moral das pessoas, e o desejo da corrupção política nos títulos. (BRANCO, 2006, p. 128).

\section{Considerações Finais}

A partir do exame desses periódicos oitocentistas foi possível resgatar um dos diversos títulos de Camilo Castelo Branco que figurou nas páginas de anúncios dos jornais daquele tempo e em formato de romance-folhetim no Brasil. Retomar as investigações sobre os títulos que circularam nas páginas dos periódicos, porém que não são mais editados ou raramente reeditados e, por isso, não são de conhecimento do público contemporâneo, é importante para traçar o percurso que determinadas obras tiveram no mercado editorial brasileiro e analisar com maior propriedade o longo e profícuo caminho percorrido pelo gênero romance após sua implementação em terras nacionais.

Nesse sentido, conseguimos observar a ampla circulação do romance Os brilhantes do brasileiro, na segunda metade do século XIX, em formato de livro, por meio dos anúncios publicados na imprensa carioca e identificar que tal narrativa competia e dialogava com grandes nomes da época, tais como Ponson du Terrail, Paul de Koch, Pinheiro Chagas, dentre outros.

Nessa perspectiva, esses reclames nos mostram também o processo de popularização desse escritor, com edições disponíveis para todos os gostos e bolsos. 
Esses dados demonstram que Camilo tinha posição de destaque no mercado brasileiro das letras, tornando-se referência também para a história da leitura no Brasil.

A partir da observação do romance Os brilhantes do brasileiro em formato de folhetim, publicado no jornal Diário de Belém, podemos constatar que Camilo fazia sucesso também do nosso lado do Atlântico, tendo em vista a quantidade de livros anunciados e publicados em folhetim no Brasil. Dessa forma, acreditamos ter cooperado para o desenvolvimento das pesquisas acerca dos caminhos da ficção camiliana em terras brasileiras.

\section{REFERÊNCIAS}

ABREU, Márcia. "Problemas de história literária e interpretação de romances". Revista Todas as Letras (MACKENZIE. Online), v. 16, p. 39-52-52, 2014.

BRANCO, Camilo Castelo. Os brilhantes do brasileiro. São Paulo: Escala, 2006.

COELHO, Jacinto do Prado. Introdução ao estudo da novela camiliana. Lisboa, Portugal: Imprensa Nacional-Casa da Moeda, 2001.

FRANÇA, L. A. O.; QUEIROZ, J. M. “A presença de Camilo Castelo Branco no periódico Diário de Belém”. In: Tânia Sarmento Pantoja. (Org.). E - book do V Congresso de Estudos Linguísticos e Literários na Amazônia. 1ed. Belém: Programa de Pós - Graduação em Letras -UFPA, 2016, v. 2, p. 110-123.

FONTES, Joana Edilza Oliveira. "Trabalhadores portugueses em Belém do Pará no início da república". In: SARGES, Maria de Nazaré; LACERDA, Franciane Gama (Org.). Belém do Pará: história, cultura e cidade: para além dos 400 anos. Belém: Açaí, 2016.

LIMA, Neila Mendonça Garcês. As narrativas camilianas no espaço folhetim do Diário do Gram-Pará na década de 1860. Dissertação (mestrado) - Programa de PósGraduação em Letras, Universidade Federal do Pará, Belém, 2014.

MOYSÉS, Tatiana de Fátima Alves. Camilo Castelo Branco: a moral a serviço das conveniências. Dissertação de Mestrado. São Paulo: USP/ Faculdade de Filosofia, Letras e Ciências Humanas, 2011.

PAIVA, Cláudia Gizelle Teles. Entre jornais, livrarias e gabinetes de leitura: a circulação dos romances-folhetins camilianos no Pará oitocentistas. Dissertação 
(mestrado) - Programa de Pós-Graduação em Letras, Universidade Federal do Pará, Belém, 2017

SALES, Germana. Folhetins: uma prática de leitura. Entrelaces (UFC), v. 1, p. 44-56, 2007.

OLIVEIRA, Paulo Motta. "Pescoceiras rorejantes de suor: os brasileiros de Camilo, uma teia atlântica”. In: VIII Congresso Luso-Afro-Brasileiro de Ciências Sociais, 2004, Coimbra. VIII Congresso Luso-Afro-Brasileiro de Ciências Sociais. Coimbra: Centro de Estudos Sociais, Faculdade de Economia, Universidade de Coimbra, 2004. 